\title{
PRECOMPETITIVE EMOTIONAL STATE OF DANCESPORT ATHLETES
}

\author{
Victoria Andreeva, Diana Karanauskienè \\ Lithuanian Sports University, Kaunas, Lithuania
}

\begin{abstract}
Background. The paper deals with the precompetitive emotional state of dancesport athletes before competition. Research aim was to analyze pre-competition emotional state of dancesport athletes.

Methods. The pre-competition emotional state of dancesport athletes was established using methods of indepth interview and participant observation. The main reasons for different types of emotional states were identified, and finally, recommendations for athletes and coaches how to overcome immoderate anxiety interfering with good competition results were developed.

Results. Precompetitive emotional state before competition may be described as a complex multi-faceted phenomenon which consists of different psychological categories such as: anxiety, arousal, stress, self-confidence, concentration. The results of the interviews and participant observation showed that precompetitive emotional states of the dancesport athletes were both positive and negative. Positive emotional state was shown by the majority of participants. There were found six reasons of positive emotional state and five reasons of negative emotional state as well.

Conclusion. To overcome the negative emotional state or reinforce positive emotional state before the competitions it is suggested to listen to pleasant music, do breathing exercises or do the mental exercise. The choice depends on the personal characteristics of athletes.
\end{abstract}

Keywords: dancesport, precompetitive state, emotions.

\section{INTRODUCTION}

I n dancesport, physical, technical and tactical preparation levels of the strongest athletes are approximately on the same level. Therefore, the result of competition depends on the level of the dancer's mental fitness. During extremely important competitions mental tension increases greatly, thus mental and psychological preparation becomes much more important. As Jones (1991) has pointed out, at the top sporting levels (at least in many sports), there is very little difference in the skill levels of the participants. It is thus often the ability to handle anxiety and stress that separates the winner and the loser. It is important to understand what the dancer feels before the competition, so that the coach could help overcome the problems of the athlete and improve the competition result.

Qualitative hypothesis of the research states that anxiety is the most frequent emotional state, but not the only one, before competition. This hypothesis is based on research of Jones and Hanton (2001) where both the facilitated and debilitated performers indicated being most "anxious". Thus, the aim was to describe and analyze precompetition emotional state of dancesport athletes.

Types of athletes' precompetitive emotional states. Pre-competition states are psychological states of athletes which are experienced before the start of a competition (Vodičar, Kovač, \& Tušak, 2012). Sport normally involves competition; competition normally tends to produce anxiety, characterized by a growth in arousal (Jarvis, 2006). Arousal may be defined as a general physiological 
and psychological activation which may vary from deep sleep to intense excitement (Gould \& Krane, 1992). According to Cashmor (2008), arousal is a diffuse model of activities, both physiological and psychological, that prepares us for a task. In sports psychology, pre-competitive anxiety is described as an unpleasant emotion which is characterized by indefinite but constant feeling of worry and dread before a competition (Athan \& Sampson, 2013). Weinberg and Gould (1995) have presented the following definition of anxiety: "a negative emotional state with feelings of nervousness, worry and apprehension associated with activation or arousal of the body". According to Jarvis (2006), anxiety is a reaction to an anticipated threat: real or imaginary. Anxiety contains two elementscognitive and somatic, which influence performance before and during competitions. The cognitive element is psychological, characterized by negative expectation about victory or self-evaluation, concern about results of the competition, images of failure and incapacity to concentrate. The somatic element is the physiological element which is associated with an autonomic arousal, and negative symptoms such as a feeling of nervosity, high blood pressure, dry throat, muscular tension, and fast heart rate (Martens, Burton, \& Vealey, 1990). Karageorghis (2007) partly supported this theory, but he added new, the third, category of the precompetitive anxiety. So he distinguished three elements of precompetitive anxiety: cognitive, somatic and behavioral. Martens et al. (1990) linked the term of arousal with the term of anxiety, so they saw pre-competitive anxiety as an arousal that was unpleasant or negative and occurred prior to competition. According to them, it is a negative emotional state that is characterized by the feeling of worry, nervosity associated with activation of the body. According to Moran (2004), factors such as fear of failure and lack of confidence cause a feeling of anxiety in athletes. Krane (1994) noted that the human body shows a lot of signals, for example: muscle tension, necessity to go to the toilet to demonstrate that it is not possible any more to maintain total control of the body.

The term stress has a broader meaning than anxiety. Stress is the process where an individual perceives a threat and responds with a series of psychological and physiological changes, including increased arousal and the experience of anxiety (Jarvis, 2006). Stress is a physical, chemical and emotional factor that causes bodily or mental tension and may be a factor in disease causation and a state resulting from stress; especially one of bodily or mental tension resulting from factors that tend to alter an existent equilibrium (Winkelhuis, 2001). According to Jarvis (2006), humans tend to feel stress when they meet demands that are difficult to meet, but which carry serious consequences in the case of failure to meet them. If stress is longterm, or chronic, it can cause serious harm to both physical and mental health. Whilst it is quite normal to experience some anxiety before competing, athletes should not feel constantly anxious and see themselves as facing insurmountable odds. Stress also can be considered as a constraining or propelling force or pressure that causes a significant change in a system; alternatively, it may be approached as the response of a system to force; or even the relationship between the two (Cashmor, 2008). In this case, by analyzing the scientific literature the precompetitive emotional state before competition may be described as a complex multifaceted phenomenon which consists of different psychological categories, such as anxiety, arousal, stress, self-confidence, and concentration.

Precompetitive emotional state of athletes in different types of sport. Hanton, Jones, and Mullen (2000) examined self-reported cognitive and somatic anxiety in 50 rugby league players and 50 target rifle shooters. As to anxiety there, they did not find any differences between two groups of athletes. In their perceptions of the effect of cognitive anxiety on performance, no differences were found, either. However, rugby players were more likely to tell that somatic anxiety had a positive impact on their performance, and shooters were more likely to say it had a negative impact.

The study with elite rhythmic gymnasts showed that the levels of precompetitive somatic and cognitive anxiety were greater during the competition than during the training session, where self-confidence and concentration scores were decreased. Analysis of physical data showed that the heart rate and time of exercise were increased while the performance was decreased in the competition compared to training session (Nassib, Mkaouer, Nassib, Riahi, \& Arfa, 2011).

According to Ikulayo (1990), there are many ways how precompetitive anxiety can affect sports performance. Firstly, for sports which require stamina, power or both at the same moment, precompetitive anxiety can greatly pull down the athlete's energy level. Secondly, in sport where 
calmness is extremely important, for example in golf, archery, free throw shooting in basketball or direct free kick in football, precompetitive anxiety can strongly intervene with the athlete's ability to stay calm. Thirdly, anxious athletes can find it difficult to be able to remain focused on the task, and finally pre-competitive anxiety can increase tension in the muscle of the throat and chest to the point where it may seem impossible to swallow or expand the chest. According to Krane (1994), precompetitive anxiety can make a powerful influence on athlete's performance. In his research he observed that the cognitive interpretation that athlete gives to a situation influences his or her performance greatly. He also added that successful athletes can interpret pre-competitive anxiety in the way to keep up their athletic performance. According to Athan \& Sampson (2013), it is usual to experience precompetitive anxiety. They said that a certain level of physical arousal is helpful and prepares athletes for competition. But they noted as well that when the physical symptoms of precompetitive anxiety are too high, they may seriously intervene with athlete's ability to show his or her best performance. According to their study it happens because the coordinated movements which are required in athletic events become increasingly difficult when the body of the athlete is in a tense state.

Jones, Hanton, and Connaughton (2007) were engaged in research in the field of the framework of mental toughness in the world's best performers. Eight performers, three coaches and four sport psychologists were chosen in order to gain a diverse representation. During this research thirteen attributes were defined that clustered under the competition dimension and were considered essential to mental toughness in a competitive situation as well as were ranked in order of importance. These attributes could be further divided into six subcomponents: belief, staying focused, regulating performance, handing pressure, awareness and control of thoughts and feelings, and, finally, controlling the environments.

Hanton, Mellalieu, and Hall (2004) defined two causal networks showing self-confidence to influence the relationship between competitive anxiety intensity and symptom interpretation. In the absence of self-confidence, increases in competitive anxiety intensity were perceived as outside of the performers' control and debilitating to performance. Under conditions of high self-confidence, increases in symptoms were reported to lead to positive perceptions of control and facilitative interpretations. To protect against debilitating interpretations of competitive anxiety, performers reported the use of cognitive confidence management strategies including mental rehearsal, thought stopping, and positive self-talk.

Precompetitive emotional state of athletes in dancesport. Sports dances belong to the group of acyclic, complicated in coordination or technically aesthetic sport that requires fast and high-quality mastering of a wide range of technical elements during the training process and perfect performance under the pressure of competitive activities (Moore, 2002). For the first time the problem of the need for development and formation of emotional stability of the athletes in the sports dance in Russia was noted by Rubshtein (Рубштейн, 2005). In particular, she emphasizes that adverse emotional states impede qualitative performance of activities such as training and competition. In the process of the competition, the dancer's anxiety and worrying reach an excessively high level, which generally has a negative impact on the effectiveness of the technical action and consequently, on the sports results. The author suggests that low levels of anxiety during competitive activity mean that the protective factors influence the body of the dancer, which makes the opening up of the technical and emotional potential of the dancer impossible. For sure, these factors have a negative impact on dancer's performance.

Already during the initial stage of preparation of the dance couples, competitions are held under the conditions full of strong rivalry and are characterized by elevated emotional stress. Stress during the competition may cause disease, but it also may not. The fact remains that stress tends to alter the existent equilibrium. The dancer may not feel the stress but it does alter his or her state of being. The reason why the dancer may not feel the stress is because he or she could be used to feeling that comes with it. Without feeling that stress the athlete might even feel something is missing (Winkelhuis, 2001). According to Winkelhuis (2001), the autonomous nervous system, which protects a human from different dangers in the world, reacts not only upon physical human threats but also mental and emotional threat. Winkelhuis (2001) divides dancer's threats into three big groups:

1) Physical threats. Physically dancers may face a lot of threats. For example, if there is a habit 
to dance 5 final dances without any rest. Other physical threats can be lack of stamina, lack of food, lack of liquids. Physical threat may come also from a lack of warm-up and cool-down, lack of experience with the new choreography or new techniques.

2) Mental threats. They come from mental thoughts, demands and desires the athlete cannot control. The thought about making a good result is decoded by autonomous nervous system as a threat because the athlete cannot decide the outcome in terms of result. Other mental threats are, for instance, the focus on what the partner should or should not to do, also the thought about judges, and other competitors.

3) Emotional threats. They come from the situations the athlete needs to change to make himself/herself happy. For example, music in the competition.

Pressure - mental, physical or emotional - does not only cause tension in the mind of the dancer. It also prevents the body from feeling free to dance as it normally could during the training session. Stress leads to short breathing high in chest, a faster heartbreak, too much consumption of energy and too tense muscles. Excitement and tension before going to the site appear as a reaction to a stressful situation, and are mobilizing huge amounts of energy, requiring release.

According to Rubshtein (Рубштейн, 2005), if we look at how it works in nature, we can see that the situation of danger mobilizes a living being and all their resources to escape or resist attacks. The rivalry, for sure, is a kind of a situation of danger - there is the possibility to lose the status in case of losing, this danger of damage to the status of the dancer is really a serious harm to a modern person, the same as the physical one. In the point of view of Rubshtein, precompetitive anxiety is an accumulation of energy which has to be thrown out during the competition. So, that is clear that in this situation energy is urgently needed to win.

Rubshtein (Рубштейн, 2005) also says that problems with coordination, losing attention on the dance floor and other difficulties accompanying the precompetitive anxiety, are caused by efforts of the dancer to keep calm. All the energy is inhibited and blocked, and this blocking takes a huge part of effort and attention and, consequently, does not let the dancer concentrate on the performance. In addition, prolonged and regular inhibition of the energy provokes uncontrollable outbursts of energy during the dancing, and then the dancer makes mistakes in competition choreography, puts too much energy to the connection with partner (pulls the partner), loses the tempo of the music and balance.

Rohleder, Beulen, \& Chen, (2007) completed five studies to examine cortisol stress responses in dancesport competitors. These five studies demonstrated that the cortisol levels were not merely from the physical strain of dancing, but also the stress of competition. Dancers were stressed more on competition days compared to noncompetition days, especially at the beginning of their careers, but the social support decreased the stress of the dancers. According to Ронь (2011), achieving a particular result in dancesport, the technique of execution of the dancing steps and complete performance in all senses depend on the mental state of mind of both partners in a dancing couple. Even the result of very experienced dancers during the competition depends on the emotional state. Highly qualified athletes practicing dancesport develop dance techniques under different conditions (a lot of couples on the dancefloor at the same time, different temperature conditions, and different slip level of the dancefloor) in order to achieve totally automatic independent coordination of the body. The most important topic in the field of psychological support of the dance couple during the preparation sessions, according to Ронь (2011), is formation of correct precompetitive emotional state. For Ронь (2011), the completely still and calm state of mind is not considered as the best mental state for achieving great performance during the execution of the competition choreography. It is necessary for the mental condition of the athlete before the competition to have an optimal level of arousal. Ron says that in this state, the dancer is able to demonstrate all technical, coordination, musical and responsiveness qualities in the best, available way. Also Ron (Ронь, 2011) just as Rubshtein (Рубштейн, 2005) confirm that disconcerting influence of the emotions can be manifested in a strong form of confusion, stiffness, low level of coordination of the body movements, slowdown of the mental processes functioning, loss of the correct rhythm of music during the execution of the competition choreography, mistakes in communication with the partner during the dance, losing control during the dialogue with the partner, in some cases even aggression. 


\section{METHODS}

Research sample. Qualitative research is an empirical study where the data is not quantifiable (Blaxter, Hughes, \& Tight, 2010). There is no formula which helps determine the number of informants to carry out a quality study (Yin, 2010), so the number of interviews was decided by the researcher following the criterion of data saturation. The targeted research group included athletes of dancesport who had competition experience of no less than seven years. The total number of the participants was thirty-one. The first four took part in the interview, and the other twenty-seven were observed during dancesport competition.

During participant observation, twenty-seven dancesport athletes were observed: fourteen females and thirteen males. The competition, which was observed during the participant observation, had the status of International Open Competition, which can be titled as the second most highlyqualified open competition in World DanceSport Federation. One of the participants of the observations was the couple of current Word Champions. Among the participants, there were also some couples of TOP-50 of World Ranking List of the World DanceSport Federation. The competitions of this level need a certain level of preparation and experience. So the participants of the observation possessed analogous experience characteristics as the participants of the interviews.

Methods. Interviews. Interviews are one of the most commonly recognized forms of qualitative research methods (Mason, 2002). In addition to what people say, it is also suggested to pay attention to the body language, moods, or attitudes of the participants, including the general environment (Mack, Woodsong, Macqueen, Guest, \& Namey, 2005).

Participant observation. The terms "observation", and in particular "Participant Observation", usually refer to methods of collecting data with the researcher immersing herself or himself in a research environment so that they can observe it at first hand (Mason, 2002). Participant observation always takes place in locations which have a relevance to the research questions and can give some more information about it. Participant observation is usually used to improve the design of other methods, such as interviews and focus groups. For example, they help to secure the cultural relevance and accordance of interview and focus group questions (Mack et al., 2005).
Qualitative content analysis of the data. Crosssectional indexing form of analyzing of the data was used during this investigation. Cross-sectional indexing of data means devising a consistent system for indexing the whole of a data set according to a set of common principles and measures. The main sense of this form is that the researcher uses a uniform set of indexing categories systematically and consistently to their data (Mason, 2002).

Research organization. The research was conducted in December, 2016-March, 2017. Each interview was agreed in advance according to convenient time and place for informants. An interview took on average 30 minutes. For busy elite dancers interviews were held intensively. Interview consisted of ten open-ended questions that allowed for individual variations (Bogdan \& Biklen, 1982). The questions and the answers were collected by the first author of the work. At the beginning of each interview, the topic of conversation was presented to each subject. The interview guide was developed covering the topics from the literature analysis. The shorthand method of recording of the information was used during the interview - the text was written skipping nonessential thoughts or repetitions. The shorthand method was preferred due to the environment of the interviews as well as the wishes of the interviewees who felt uneasy knowing that their voices were recorded, and this caused extra stress to them. Besides, the method had been well mastered by the researcher-interviewer. Within 24 hours of the interview, the shorthand notes were expanded into sentences. This task was done using a computer.

The Participant Observation took place on the 19th of February, 2017, during International Competition "Trofeo Low-Cost Eta Beta Danze" in the sports hall of Prato city in Italy. The group of athletes taking part in the International Open Competition in Standard and Latin program was observed. The Participant Observation took place from 9.00 till 10.30 a.m., with the assigned beginning of the competition at 10.30. The participant observation data was done in the form of the detailed field notes that the first researcher recorded in a field notebook. The shorthand method of recording the information was used - the text was written using abbreviations. Within 24 hours of the participant observation, the shorthand was expanded into sentences. This task was done using a computer. All the collected information and data were analyzed using cross-sectional indexing form 
of analysis. A special set of categories was applied systematically and consistently to the data.

\section{RESULTS}

All the participants pointed out that emotional state had a great influence on their performance during the competitions. Emotional states of dance sport athletes can be divided into two major groups: positive and negative. Organization of research results is presented in Figure 1.

External indications of each state include all actions which are visible (physical state, specific movements of the body, gestures). The internal indications involve the mental part, the state of mind of the athlete. During the research, the reasons for different emotional states were established as well.

Positive emotional state. External indicators. First of all it is worth noting that all participants with the prevailing positive state of mind mentioned that they had a slight arousal before the competition.
The main external indicators of positive emotional state are represented in Figure 2.

As the observation field notes show that the smile is the major indicator of external positive state of mind. In the international competition, persons could be seen listening to music, telling jokes and chatting with friends. One pattern noticed during the interviews was that male dancers were more predisposed to telling jokes with others male friends and laughing. Besides, male participant $\mathrm{D}$ remarked "I laugh and joke with friends who are present there, I listen to POP music". This pattern was confirmed during the observation of the competition as well. There, the boys spent much more time laughing and making jokes than girls. Female participants preferred the easy chatting in the group with other female dancers. It was interesting to note that one dancer was also observed praying and crossing himself before the start of competition. These actions indicate the external expression of being religious, which can take place before the competition.

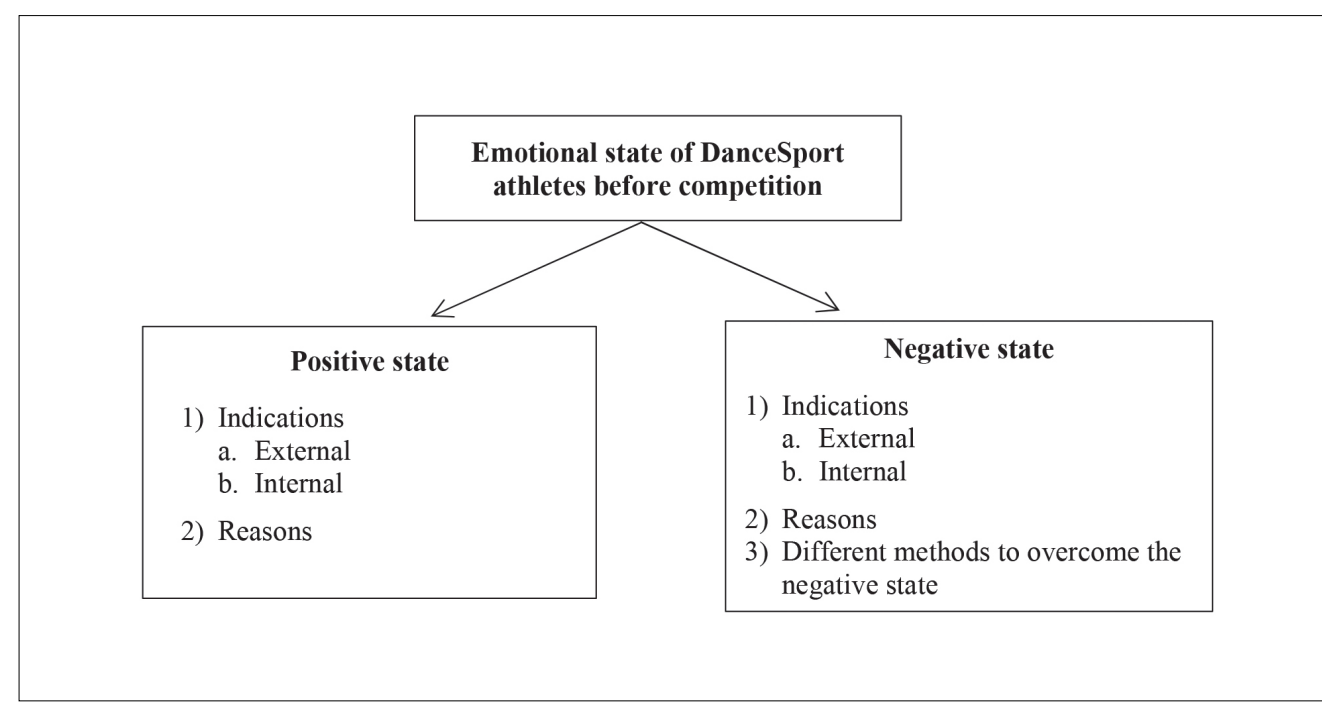

Figure 1. Organization of research results

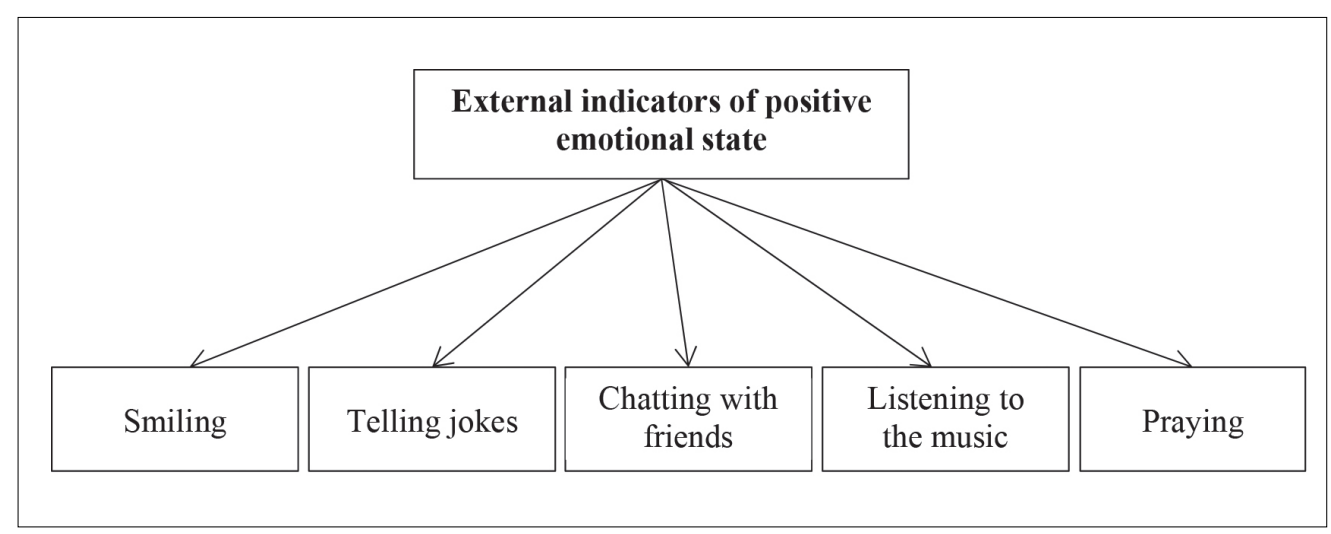

Figure 2. The main external indicators of positive emotional state 
Figure 3. The main internal indicators of positive emotional state

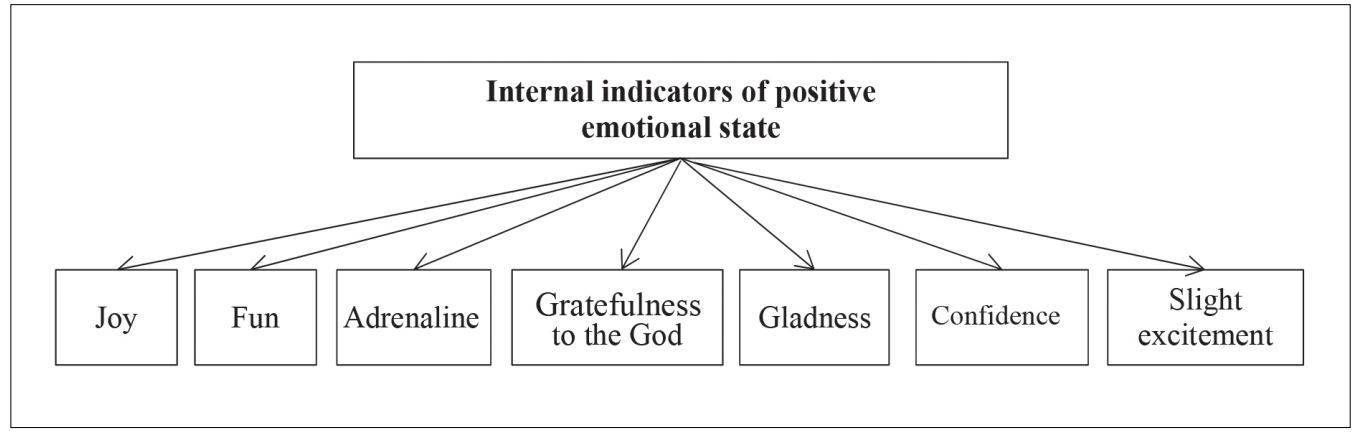

Internal indicators. The main internal indicators of positive emotional state are presented in Figure 3.

If we speak about internal indicators, the most common sense experienced is joy. Another important point is the sense of the adrenaline mentioned by a couple of participants, e.g. "I like to compete in the competition! I am a really a gambling man. When I come to the competition, and hear music, the dancing passion adds to my dance a lot of bright moments and emotions!" (Participant D). From the facts represented below we can conclude that in some cases gratefulness to God and general connection with the religion may take place, too e.g. "I am grateful to God and all my family for having the ability to do it the day by day..." (Participant B). As it was already mentioned, the most experienced and positively-minded participants marked the presence of slight excitement. Some quotes of participants A and B confirm this fact: "Anyway... in any competition I feel a little bit nervous..." and "For sure, there is some excitement". Most different reasons of positive emotional state were noted. It is important to say that participant B may be characterized as the most positively-minded participant of the research. During the whole interview she was quiet and relaxed, kept a pleasant tone of voice and smiled a lot. There was definite and very strong sense of positivity and serenity in all her answers. She named some general positive feelings before starting the competition: joy, fun, slight excitement, feeling confident and assured. She talked a lot about the reasons for each state: "Joy, because again I can go to the floor and show my dance. Fun, because the dance is what I really like to do in all my life. ... usually I am sure I look great on the dance floor, my dress and make up look good... When I know for sure that I remember all, even the smallest details of the choreography, and then I feel that my performance is really great. ... Anyway, me and my partner have worked before the competition and we are always feel confident and sure in our performance".
Participant $\mathrm{C}$ told a lot about his positive mood before the competition as well. He noted quiet the same categories as Participant B: joy and gladness. "Most often, Ifeel emotions with a "plus" ... Do you understand? It means something positive. After all, I am doing things that I really love. Dancing means a lot in my life. I plan to dedicate my whole life to dance. So that's why, I feel the joy and gladness when I am dancing in competition". Moreover, both participants $\mathrm{B}$ and $\mathrm{C}$ highlighted the fact that they really loved dancesport and the possibility to practice this sport makes them really happy.

Reasons for the positive emotional state. The key reasons of positive emotional state mentioned by research participants were:

1) Ability to demonstrate proper qualification to judges and the audience

"Because I can finally again enter the dance floor and show my dance to the audience... Show all my abilities and to show the result of many hours of hard work in the dance school and gym..." - Participant B

2) Identifying dancing as thing the person likes to do

"The dance is what I really like to do in all my life..." - Participant B

"After all, I'm doing thing that I really love. Dancing means a lot in my life" - Participant C

3) Being sure of the perfect total looks (competition dress, make-up, hairstyle)

“...usually I'm sure I look great on the dance floor, my dress and make up look good..." Participant B

4) Clear understanding of all steps and details of the competition choreography

"When I know for sure that I remember all, even the smallest details of the choreography, then I feel that my performance is really great...." - Participant B

"I prefer to go to the dancefloor to warm up, and repeat my choreography. As the size of the dance floor may be different a bit, for me 
as partner, is important to repeat the whole choreography" - Participant C

5) Confidence about the preparation work done with the partner and coach

"Anyway, me and my partner have worked before the competition and we always feel confident and sure in our performance." Participant B

6) Support of the public

"And I really like when in the competition there are a lot of spectators. They give me a lot of good, positive energy and it's very cool! During my dancing I am trying to keep in touch with the audience. After all, we dance not only for ourselves, but also for all people who are watching and supporting us!" - Participant C

Negative emotional state. External indicators. The main external indicators of negative emotional state are presented in Figure 4.

As the observation field notes show, the major external indicator of negative emotional state is changing facial expressions. During the competition, this switch of expressions was clearly visible. Many times the faces of the athletes on different reasons, from calm and smiling were turned into displeased, sad, angry and annoying ones. One girl who was noticed during the observation of the international competition was even going to cry. Participant $D$ spoke about changes of the facial expressions as well; he identified this indicator as more frequent and visible "My facial expression changes immediately and unconsciously, making visible my uncomfortable situation." Another indicator which was noticed during the research is using the particular tone of voice during the communication with the partner. Participant A confessed that sometimes his tone of voice can be unpleasant and the connection with the partner not always correct - "I can speak not in the correct way with my partner using angry voice sometimes but it's all the fault of the anxiety before competition... ". Also during the observation of international competition the using of particular tone of the voice was noticed. There was noticed the boy who was speaking with angry voice with his partner during the warm-up, the girl who was using disgruntled voice to communicate with her partner. Beside of that, some typical indicators of stress take place before the dancesport competition. Participant $\mathrm{D}$ marks the respiratory difficulties and shortening of the breath - "As a knot that closes your throat and does not let you breathe..., ... and the breath becomes shorter...". As the observation field notes show among the external indicators there is also sweating of the palms, because during the observation was noted the boy who was drying the palms after just concentrating before the competition.

Internal indicators. During research, the following internal indicators of negative state were identified: anxiety, nervousness, fear, worry, annoyance. These indicators are shown in Figure 5.

Feeling of anxiety is the most common negative state. It is interesting to note that the word "anxiety" was used by all participants of the research, even if their dominant emotional state was positive. Participant B considered slight anxiety as the normal state before the competition for each athlete: "Of course during the competition there is excitement and may be even some anxiety. I think this is the normal state." The opinion of the Participant B coincided with the words of Participant $\mathrm{C}$ : "Therefore, before the start the each comp, I feel a little bit of pre competition excitement, sometimes even anxiety, but anyway I think it is normal and natural." Moreover, during the interview with Participant $\mathrm{C}$, the strong feeling of responsibility for the performance was emphasized. He used the word "responsibility" many times and the pressure of the responsibility about his partner, his family and coach was marked by different expressions: "I understand all the responsibility not only about

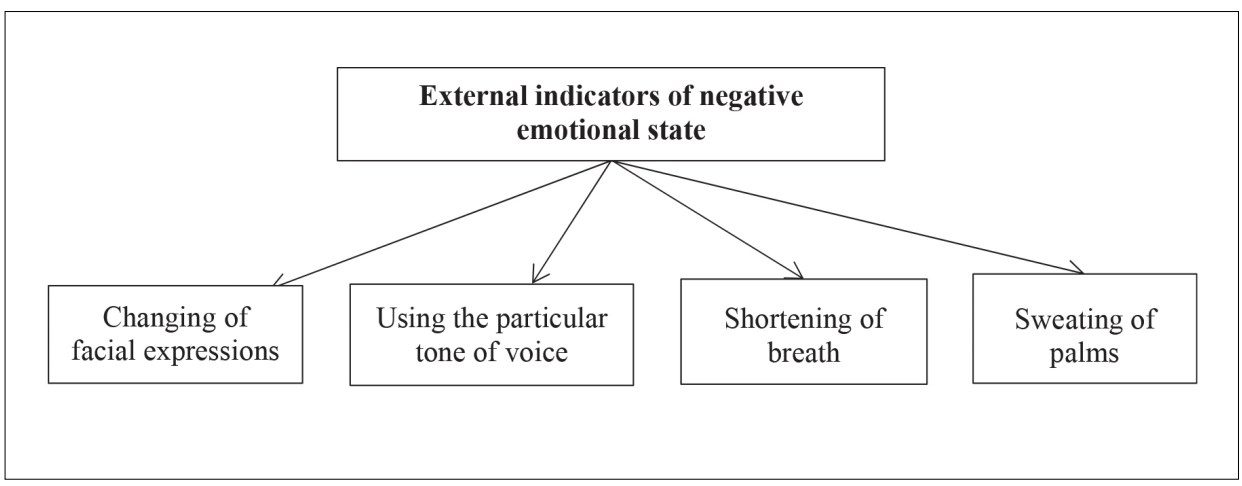

Figure 4. The main external indicators of negative emotional state 
Figure 5. The main internal indicators of negative emotional state

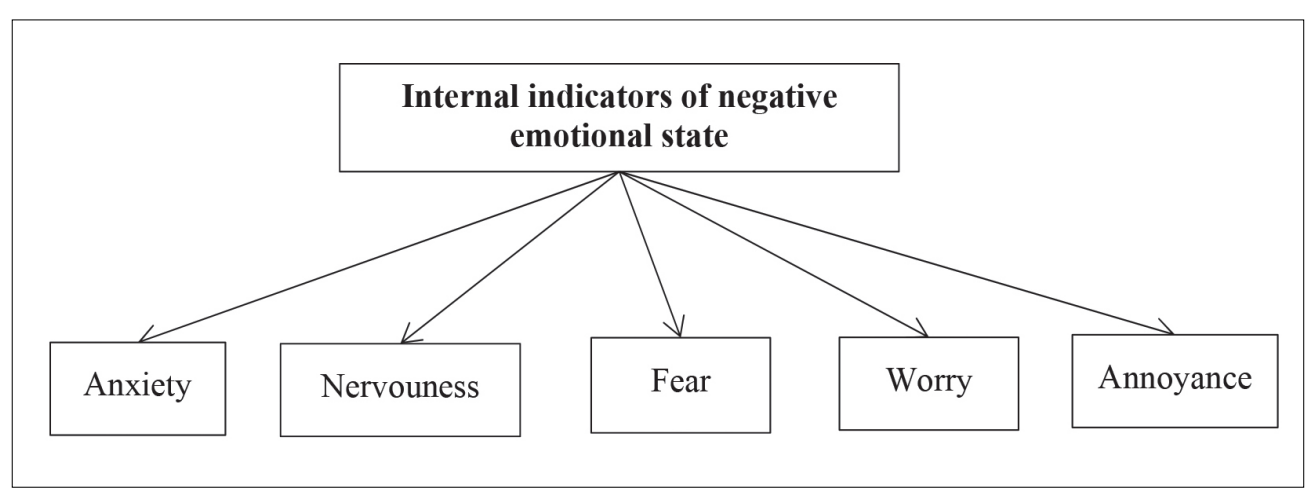

my performance, but also about my partner, my coach. Because we, as a couple are representing his work with us... also for sure my parents... I try to make them be proud of me... for me personally it's very and very important... Also I want to feel myself the strong part of our couple. I would like to be reliable partner and give as much support as possible to the other part of the couple. I am a male part of the couple and from me depends really a lot of different things." Also Participant $\mathrm{C}$ was unique to demonstrate the feeling of annoyance before the competition. Especially he emphasized it when speaking about the uncomfortable time table of the competition. - "It's surely is annoying and puts me out of my internal balance". Some participants noted feeling nervous on the day of competition. "I feel very nervous generally about each single thing on the day of competition before the beginning, but once it starts all the worries go away"-remarked Participant D. Participant A also mentioned being nervous before the competition: "Anyway... in any competition I feel a little bit nervous... Of course in small competitions I am a little bit more secure but if the competition is big a start to be very nervous..." From this expression it can be also noted that for this participant the level of the nervous state depends on the importance of the competition. One of the patterns noticed is that despite various reasons the common feeling of fear was very frequent as well: "May be I am afraid that something will go wrong, you know... There are so much different factors... My partner... The judges...", "On the other hand fear of "mistakes" and disappoint the expectations that you have created about yourself or that friends, family and coaches have made about you." - Participants A and D. The feeling of worry was mentioned by participants as often as the feeling of nervousness. "I am little bit worried about my performance and my result as well..., ...I start to worry if me and my partner have enough time to prepare ourselves..",
"I worry about the judges as well, I have a fear that they will not like my dancing...". It shows that the feeling of worry was mentioned by participants as well.

Reasons for the negative emotional state:

1) Uncertainty about the competition choreography "May be I am afraid that something will go wrong with the choreography, you know..." Participant A

2) Improper communication with the partner "... I can speak not in the correct way with my partner using angry voice sometimes but it's all the fault of the anxiety before competition..." Participant A. During the observation of the competition, some dancers were noticed using unpleasant tone of voice with their partners.

3) Difficulties with the competition looks (dress, shoes, hairstyle, make-up)

This is one of the most frequent reasons of negative state of the dance sport athletes. When participants talked about the most stressful competition in their career, half of them associated it with forgetting or losing something from their competition stuff. Participant B said that once she forgot her competition shoes at home - "An hour before the start of the competition I understood that my shoes for standard program were at home. Can you even imagine? It was very unexpected and stressful...". Participant $\mathrm{C}$ told that one time the air lines lost his bags with the shoes and dance dress just before the competition: - "I was shocked! Tomorrow we have competition, and I have no clothes and no shoes... Tanning, hair styling stuff, and everything I need for preparing myself to the competition was in my luggage". During the observation a lot of dancers had negative emotions because of this reason. One girl was going to cry because she had broken her dress and needed to fix it as soon as possible, the other girl seemed dissatisfied with her make up.

4) Pressure of responsibility and expectations made by coach, parents and friends 
"I think I am anxious a bit before competition because I understand all the responsibility not only about my performance, but also about my partner, my coach. Because we as a couple are representing his work with us... also for sure my parents... I try to make them be proud of me... for me personally it's very and very important..." - Participant C.

"On the other hand fear of "mistakes" and disappointment of the expectations that you have created about yourself or that friends, family and coaches have made about you" Participant D

5) Judges

"I worry about the judges as well; I have a fear that they will not like my dancing... " Participant D. Also during the interview participant A mentioned the word "judges" when he was talking about factors which sometimes give him negative emotions.

Different methods to overcome the negative state. Different ways were identified to overcome the negative emotional state before the competition. All methods can be divided into two major groups: mental and physical. The mental group includes all psychological techniques which are used to overcome the negative emotional state. The physical group involves all actions that athletes do to overcome the negative emotional state. In the physical group the most common method is listening to the music. It is interesting to note that collocation "listen to music" was used by all participants of the interview. In addition, the major part of participants named this method of overcoming the negative state as one of their favorites. The field notes of the observation show that most dancers listen to music before the start of the competition, which makes this method one of the most popular. Participant B told about the breathing exercises as well: "Also before the competition I like to do breathing exercises. I try to focus on how I breathe. It helps me a lot". Some persons prefer to enjoy the company of their friends, for example, Participant D: "I laugh and joke with friends who are present there...". This fact was also confirmed during the international competition, where there were some boys also joking and laughing with the friends. Participant $\mathrm{C}$ spoke about other methods which help him overcome the negative state: "Before the competition, to keep calm and feel fine I prefer to go to the dancefloor to warm up and repeat my choreography. As the size of the dance floor may be different a bit, for me as partner, it is important to repeat the whole choreography". Generally, this method is quiet frequent as well because before the competition really a lot of dancers not only warm up their muscles but also repeat their choreography.

In the mental group, two methods were emphasized which have opposite bases. Despite having two completely opposite bases, these two methods have the same popularity among the dancers. The first method was trying to concentrate on the performance itself, on the technical quality and the connection with the partner without thinking about the result, judges or opponents. The example of using this method is the words of the Participant A and C: "I try not to think about the result, I am concentrating on my dancing and technical quality...", "Before the competition I try to concentrate on the most essential things performance, my partner". The other method is trying to divert the attention from the competition in general, think about abstract topics and try to isolate the mind as well. This method was used by the Participants B and D:" First of all I try to distract from thoughts about the performance... I try to think about abstract topics...", "I always try to divert my attention from the competition itself".

\section{DISCUSSION}

The aim of this research was to analyze pre-competition emotional state of dancesport athletes. This was achieved by analyzing the answers of the participants of the interviews and analyzing the results of participant observation. In accordance with Jones and Hanton (2001), we predicted that the anxiety emotional state would be the most frequent among dancesport athletes. In general, the way the anxiety is expressed among dancesport athletes was demonstrated across all participants of the interview and also some persons who were observed. Actually, all participants of the interviews used the word "anxiety", even if in some cases the participant used the word "slight". During the observations, not all persons had the external indicators of anxiety, some of them seemed calm. Anyway the majority of dancers during the observation had the external indicators of anxiety. Generally, there was no clearly defined division between positive or negative states of mind, but in all cases one of the states was strongly dominant. Positive state of mind was shown by the majority of participants. It is interesting to add that 
positive emotional state was demonstrated by most experienced participants. Dominant negative state was shown by fewer participants and these athletes had less experience than the athletes who showed the dominant positive state of mind. So, the current findings provide full support for one of the points of the work by Rohleder et al. (2007). According to Rohleder et al. (2007), dancers were stressed more on competition days, especially at the beginning of their careers. Actually this statement got full support because in the investigation the highest anxiety level was shown by the competitors with the lowest experience. Some of the current findings corresponded to the work by Winkelhuis (2001). Winkelhuis (2001) suggests that stress leads to short breathing high in chest, a faster heartbeat, too much consumption of energy and too tense muscles. In this case, if we can interpret stress as a negative state, we get a full support for the opinion Winkelhuis (2001) because the participants of the investigation mentioned this term during their interviews. Also during the interviews, indicators of both emotional states were identified as well as reasons corresponding to each state. Also there is an interesting relationship between the results of the investigation and the opinion of Ron (Ронь, 2011). In her point of view, the technique of execution of the dancing steps and complete performance in all senses depend on the mental state of mind of both partners in a dancing couple. However, during the investigation clear understanding of all steps and details of the competition choreography was indicated as one of the reasons of positive emotional state of the dancers. So, if the dancer has a clear understanding of all details of the choreography, this will lead to the positive mental state, which will help the dancer perform his choreography better in the competition. It is important to note that the findings of the current investigation emphasize significant relationship between positive and negative emotional state of dancesport athlete. No one athlete feels only negative or positive emotions before the competition. The results of the interviews show that even if the athlete feels mostly positive, slight anxiety will take place, and if the athlete has the dominant negative state of mind, the feeling of joy or fun will appear as well. This mixed relationship between positive and negative emotional states shows versatility and complexity of pre-competitive emotional state phenomenon.

Another important aspect of this investigation is emphasizing the reasons of both groups of emotional states. It is extremely important because when the reasons of each state are clear, it is easier for the coach or athlete alone to avoid the negative state or maintain the positive state. The current findings provide full support for other points in the work by Rohleder et al. (2007) as well. The fact that the social support decreased the stress of the dancers (Rohleder et al., 2007) was confirmed as well as the support of the public was characterized as one of the reasons which lead to the positive emotional state of dancesport athletes before competition. The current findings also found support for some opinions of Ikulayo (1990). Some of the participants of the interview noticed that they found it difficult to be able to remain focused. It was also mentioned that pre-competitive anxiety state increased tension in the muscle of the throat and chest to the point where it seemed impossible to swallow or they had other respiration difficulties. The other interesting pattern of the observation is that the reasons for negative state like "difficulties with the competition looks" are mostly related with female part of the dancers. It suggests that the females among the dancers care much more about details in the competition looks than their male counterparts. During the investigation we observed some methods which dancesport athletes used to overcome negative emotional state. One particular thing was noticed that two mental methods were based on two completely different views on concentration before competition. This paradox of using two completely different methods to overcome the negative state may be based on particular individual characteristics of each single dancer. Interestingly, the findings of the current study provide some support to research findings by Rubshtein (Рубштейн, 2005) and Ron (Ронь, 2011). The basic external indicators of negative state, for example, stiffness, low level of coordination of the body movements, loss of correct rhythm of music during the execution of the competition choreography, mistakes in communication with the partner during the dance, losing control during the dialogue with the partner, mostly corresponded to the indicators established by Rubshtein (Рубштейн, 2005) and Ron (Ронь, 2011). Unfortunately, there is not so much research done in the field of dancesport. For sure, it is connected with very young age of this discipline as a sport. Subsequently, future research to expand the knowledge in this field should increase the number of participants and the number of observed competitions. 


\section{CONCLUSIONS}

Precompetitive emotional state before competition may be described as complex multi-faceted phenomenon which consists of different psychological categories: anxiety, arousal, stress, self-confidence, concentration. Precompetitive emotional states of the dancesport athletes could be combined into two major groups: positive and negative. Positive emotional state was shown by the majority of participants in high-performance sport.
All the participants of the interview used the word "anxiety", so it is the most popular psychological state for the dancesport athletes before competition, which has both positive and negative sides. Positive emotional state was shown by the majority of participants and it helped them better concentrate for their performance.

Future research should focus not only on highclass athletes, but also on the athletes of medium and low levels.

\section{REFERENCES}

Athan, A., \& Sampson, U. (2013). Coping with precompetitive anxiety in sports competition. European Journal of Natural and Applied Sciences, 1(1), 1-9.

Blaxter, L., Hughes. C., \& Tight, M. (2010). How to research. London: Open University Press.

Bogdan, R., \& Biklen, S. (1982). Qualitative research for education: An introduction to theory and methods. Boston: Allyn and Bacon.

Cashmor, E. (2008). Sport and exercise psychology: The key concepts. London: Routledge.

Gould, D., \& Krane, V. (1992). The arousal performance relationship: Current status and future directions. Champaign: Human Kinetics.

Hanton, S., Jones, G., \& Mullen, R. (2000). Intensity and direction of competitive state anxiety as interpreted by rugby players and rifle shooters. Perceptual and Motor Skills, 90, 513-521. doi: https://doi.org/10.2466/ pms.2000.90.2.513

Hanton, S., Mellalieu S., \& Hall, R. (2004). Self-confidence and anxiety interpretation: A qualitative investigation. Psychology of Sport and Exercise, 5, 477-495.

Ikulayo, P. (1990). Understanding sports psychology. Lagos: Eaitch Marina.

Jarvis, M. (2006). Sport psychology. A student's handbook. London: Routledge.

Jones, G., Hanton, S., \& Cannaughton, D. (2007). A framework of mental toughness in the world's best performers. The Sport Psychologist, 21, 243-264.

Jones, G., \& Hanton, S. (2001). Pre-competitive feeling states and directional anxiety interpretations. Journal of Sports Sciences, 19, 385-395.

Jones, G. (1991). Recent developments and current issues in competitive state anxiety research. Psychologist, 4, $152-155$

Karageorghis, C. (2007). Competition anxiety needn't get you down. Peak Performance, 243, 4-7.

Krane, V. (1994). Comparative anxiety, situation criticality and softball performance. The Sport Psychologist, $8,58-71$
Mack, N., Woodsong, C., Macqueen, K., Guest, G., \& Namey, E. (2005). Qualitative research methods: A data collector's field guide. North Carolina: Family Health International.

Martens, R., Burton, D., \& Vealey, R. (1990). Competitive anxiety in sport. Champaign: Human Kinetics.

Mason, J. (2002). Qualitative researching. Second edition. London: SAGE Publications.

Moore, A. (2002). Ballroom dancing. $10^{\text {th }}$ edition. London: Routledge.

Moran, A. (2004). Sport and exercise psychology: A critical introduction. London: Routledge.

Nassib, S. H., Mkaouer, B., Nassib, S., Riahi, S. H., \& Arfa, Y. (2011). Precompetitive anxiety effect on concentration and performance on elite rhythmic gymnastics. Science of Gymnastics Journal, 6(1), 23-32. Rohleder, N., Beulen, S., \& Chen, E. (2007). Stress on the dance floor: The cortisol stress response to socialevaluative threat in competitive ballroom dancers. PSPB, 33(1), 69-84. doi: 10.1177/0146167206293986

Vodičar, J., Kovač, E., \& Tušak, M. (2012). Effectiveness of athletes' pre-competition mental preparation. Kinesiologia Slovenica, 18(1), 22-37.

Weinberg, R., \& Gould, D. (1995). Foundations of sport and exercise psychology. Champaign: Human Kinetics.

Winkelhuis, M. (2001). Dance to your maximum. Dongen: www.DancePlaza.com.

Yin, R. (2010). Qualitative research from start to finish. New York: Guilford press.

Рубштейн, Н. (2005). V начиональный конгресс тренеров и судей ФТСР. Лекции по психологии. [Viewed 2016, December 10]. Retrieved from http:// www.dancesport.ru/articles/articles_40/art_68.phtml.

Ронь, И. (2011). Проблемы эмоциональной устойчивости в спортивной деятельности танцевальных пар. Психология и педагогика: методика и проблемь практического применения, 19(1), 32-36. 